\title{
“Type" as Central to Perceptions of Breed Differences in Behavior of Domestic Dog
}

\author{
Tracey Clarke \\ Animal Behavior, Cognition and Welfare Research Group, School of Life \\ Sciences University of Lincoln, United Kingdom \\ tclarke@lincoln.ac.uk
}

Daniel Mills

Animal Behavior, Cognition and Welfare Research Group, School of Life Sciences University of Lincoln, United Kingdom

\section{Jonathan Cooper}

Animal Behavior, Cognition and Welfare Research Group, School of Life Sciences University of Lincoln, United Kingdom

\begin{abstract}
A survey was designed to explore the effect of type classification on perception and expectation of a dog's behavior. The survey focused on two forms of presentation: the effect of visual image versus breed name in the identification of a breed as a dangerous dog type, and the effect of breed group classification on expectation of a dog's level of aggressiveness. The findings have serious implications for Staffordshire Bull Terriers. Respondents were over 5 times more likely to misascribe by image alone the Staffordshire Bull Terrier as a dangerous breed as defined under the United Kingdom's Dangerous Dogs Act 1991. Furthermore, the classification of Terrier attracted high scores in relation to type-specific aggressiveness. These findings highlight the need for more research on personal perception of supposedly dangerous dog breeds to better understand and explain this phenomenon, leading to better protection of the public and better welfare outcomes for dogs.
\end{abstract}

\section{Keywords}

aggression - breed - dog - legislation - perceptions - stereotyping 


\section{Introduction}

The domestic dog is a biological and cultural product; the development of dog breeds is an ongoing and dynamic process. A review of the literature identifies distinct stages of development in Europe, from earlier dog types selected for function to later types selected for physical novelty (Harcourt, 1974; CluttonBrock, 1984; Dennis-Bryan \& Clutton-Brock, 1988; Thurston, 1996; Bellwood, 2004; Kalof, 2007). While there have been changes in the selection of breeds, most notably from function to form (Svartberg, 2006), the legacy of type classification continues to inform public perception of breeds and interpretation of their behaviors. The endurance of such type classification may be explained by the same rationale underpinning the use of stereotyping in humans - that it provides a simplified representation held to characterize the typical individual of a group from which to manage our understanding and expectations of behavior (Oakes, Haslam, \& Turner, 1994; Coltrane, \& Messineo, 2000; Jones, 2012).

Most breeds no longer are solely bred for original function, and yet this form of classification continues to be applied by Kennel Clubs across the world and is reflected in breed-specific legislation such as the Dangerous Dogs Act (1991) in the United Kingdom. It is suggested that classification by "type" continues to play a role in widespread perceptions of differences in behavior between breeds of domestic dog and our understanding of canine behavior "problems" (Askew, 1996), particularly in relation to supposedly "dangerous" and "aggressive" dogs.

Here we report the findings of a survey on public perception of breed types in the United Kingdom. We identified three populist sources of information that might contribute to the public's use of type classification in understanding canine behavior and in particular perception of aggressive behavior.

The first source was the Kennel Club Breed Standards. The U K Kennel Club describes itself as, "an indispensable reference book" (The Kennel Club, 2003, 2011, p. 8) to registered breeds and purports to provide the reader with a useful description or "word picture" (The Kennel Club, 2011, p. 10) of the collective temperament of particular breeds as groups manifesting particular behavioral traits. For example, members of the Terrier group are commonly described as "courageous" and/or "fearless" (The Kennel Club, 2011, pp. 156, 157, 166, 168, 174, $176,189,190,196,202)$, and the popular terrier breed, Staffordshire Bull Terrier, as "traditionally of indomitable courage and tenacity" and "renowned for his courage, which unfortunately can lead him into bad ways with other dogs" (The Kennel Club, 2011, p. 202). In contrast, members of the Toy group are 
collectively described as possessing "charm and personality" and possessing "qualities that have made many of the toy breeds so popular as family pets" (The Kennel Club, 2011, p. 17).

Secondly, type classifications are often used in common parlance to provide a short-hand descriptor of particular behavioral traits and widely used in the media. Thus, the terrier classification is commonly used as a simile to emphasize tenacity (Oxford Dictionaries, 2014) and similarly "pit bull" is commonly applied to a person to describe their strength, power, aggressiveness, and tenacity; a notable example is the South African legal prosecutor Gerrie Nell (Cowell, 2014).

The third source was legislation; it is suggested that public perception of dog breed types in the UK has been influenced by the DDA 1991. This breedspecific legislation, underpinned by biologically deterministic assumptions of behavior, identifies particular dog types as supposedly dangerous and a threat to public safety. Within this breed-specific legislation, its rationale is defined as follows:

An Act to prohibit persons from having in their possession or custody dogs belonging to types bred for fighting; to impose restrictions in respect of such dogs pending the coming into force of the prohibition; to enable restrictions to be imposed in relation to other types of dog which present a serious danger to the public; to make further provision for securing that dogs are kept under proper control; and for connected purposes. (DDA 1991, p. 1)

Section 1 of the Act stipulates that caregivers of the "types of dog known as a pit bull terrier" and three other breed types (Japanese Tosa, Dogo Argentino, and Fila Braziliero) must fulfill certain strict requirements. These requirements include keeping the dog muzzled and on a lead at all times while in a public place, having the dog microchipped, keeping the dog insured against third-party liability, and having the dog neutered with the aim that these types of dog would eventually become extinct in the UK. The dogs are also required to have their details registered on the Index of Exempted Dogs maintained by the Department of Environment, Food and Rural Affairs (DEFRA) on behalf of the UK Government.

Under current legislation in the UK, dogs are identified as a "pit bull type" if they meet a "substantial" number of characteristics defined in the 1993 standard. Of the 100 points set out in this standard, 9o points refer to morphological conformation such as muscular build. The remaining 10 points refer to temperament and behavioral characteristics. The court is to presume that any 
dog alleged of being a pit bull type is such a type, unless the accused can show otherwise (Radford, 2001).

In addition, it is suggested that the use of these type classifications becomes particularly prevalent in society during periods of moral panic when there is a perceived threat to the social order. This was the case in the UK in the late 1980s. An increase in reporting of dog bites in the tabloid press featuring particular dog types led to increased public concerns regarding this "problem" and a demand for a government response (Podberscek, 1994). Interested in presenting itself as "in touch" with these populist concerns, and faced with a "forced choice" (Lodge \& Hood, 2002) the Conservative government of 1991 hastened DDA 1991 through Parliament in a day (Hansard, 1992). Thus, in the late 1980 in the UK certain dog types came to symbolize the problem of aggressive and "out of control" dogs during a period of moral panic when, "a condition, episode, person or group of persons emerges to become defined as a threat to societal values and interests; its nature is presented in a stylized and stereotypical fashion by the mass media" (Cohen, 2002, p. 1).

Type classifications serve to activate perceptions and expectations about the characteristics and behaviors of any individual perceived to be a member of a stereotyped category irrespective of the individual's actual behaviors, and are often employed by the media due to their wide accessibility to the public. Research suggests that "newsworthy" events that can be readily recalled from memory have an effect on human judgment known as the "availability heuristic" (Tversky \& Kahneman, 1973). The disproportionate and salacious nature of media reporting of dog-bite incidents (Levene, 1991; Podberscek, 1994) serve to inform public perception of the threat posed by supposedly dangerous dog types and set in motion a deviancy amplification cycle-images of deviance in the media, societal reaction, increase in images of deviance in the media, and escalation in public reaction (Cohen, 2002).

In this deviancy-amplification cycle the media reporting of the American Pit Bull Terrier as a modern day "folk devil" satisfies what Cohen (2002) has identified as the processes required in symbolization for the mass communication of negative stereotypes. Indeed, recent research suggests similarities in the British news media between the representation of "aggressive dogs" and other demonized groups such as "sex offenders" (Orritt \& Harper, 2013). In exploring the representation of "aggressive dogs" in the British news media, these researchers found that fatal dog bite stories scored highly in "newsworthiness," particularly in relation to negativity and unambiguity. That is, the "emotional risk-based" media reporting of dog-bite incidents typically included an emotional interview of close relatives describing the victim and events preceding their death/injury and typically involved succinct narratives relying on a clear angel/demon dichotomy, particularly when incidents involved children. Dogs 
were frequently referred to as "devil dogs," and the children were typically portrayed as angelic and innocent victims.

While moral panic and the development of folk devils has been widely explored by sociologists and criminologists relating to perceptions of race, crime, and the symbols or folk devils that come to represent populations (Becker, 1963; Hall, Critcher, Jefferson, Clarke, \& Roberts, 1978; Cohen, 2002), public perception of dog types and supposedly dangerous dogs remains a relatively under-researched subject of study (Podberscek, 1994; Delise, 2007) despite their image being inextricably bound to the most enduring folk devils in the UK-young, working class supposedly "violent" males (Cohen, 2002; Jones, 2012).

The issue of identification remains particularly problematic in the case of the DDA 1991, as the ambit of the term "type" is unclear (Radford, 2001). The public are unreliable in their identification of supposedly dangerous dogs (Delise, 2007). Visual dog breed identification is difficult even for experienced observers (Voith et al., 2013), with a lack of consensus even amongst experienced dog handlers such as shelter staff about what constitutes a pit bull terrier (Hoffman, Harrison, Wolff, \& Westgarth, 2014).

In addition to problems of identification, accuracy or "correctness" of applying type descriptions (Mayr, 1999), explanations of breed differences in behavior are challenged by a review of the literature on breed differences in behavior, which suggests that both traditional and genetic methods of grouping breeds may not be validated by behavioral research (Mehrkam \& Wynne, 2014). Furthermore, the findings of human-dog interaction studies showed significant cross-cultural differences in personal perception of the behavior of dog breeds (Bradshaw \& Goodwin, 1998; Takeuchi \& Mori, 2006; Wan, Kubiniyi, Miklosi, \& Champagne, 2009), suggesting an association between caregiver characteristics and the prevalence of canine behavior "problems" (Serpell, 1996; Jagoe \& Serpell, 1996; Podberscek \& Serpell, 1997; Bennett \& Rohlf, 2007). A review of fatal dog-bites cases in the United States (Gladwell, 2006) found that dogs who had bitten people were, in many cases, socially isolated because their caregivers were socially isolated. Consequently, it was argued that they were "vicious" because they had caregivers who wanted a "vicious" dog, with behavioral traits such as aggression reinforced through training techniques incorporating physical or verbal punishment (Hiby et al., 2004; Byrne, 2009).

The rationale underpinning this research is informed by labeling theory (Becker, 1963) also known as social reaction theory. Labeling theory is concerned with the effect on individuals of terms used to describe or classify them. It suggests that the use of language is central to our construction of social reality and the formation of negative stereotypes informs our understanding and expectation of the individual's behavior. Far from being a neutral tool of 
inquiry, language plays a significant role in the perception of animal behavior. A useful review of the significance of language in portraying animal behavior is provided by Crist (1999).

Clearly the classification of particular dog types as "dangerous" in breedspecific legislation such as DDA 1991 has serious welfare implications for individual dogs classified under these terms. Such legislation suggests that individual dogs of a morphological breed type are more dangerous and a greater threat to public safety than others, in addition to tacitly sanctioning somatotyping and biological determinism as useful and relevant explanatory models of understanding canine behaviour. As such the DDA 1991 provides a relevant and topical focus to this research.

Therefore, the two research questions of interest in this study were: (1) What effect does the material offered to aid identification of a dog type (i.e., either the name of the breed or a photographic image) have on the labeling of a dog as being of a "dangerous" type as defined in the DDA 1991; and (2) What effect does dog breed group classification have on perception of particular behavioral traits?

The issue of identification of dangerous, as defined by the DDA 1991, is the focus of the first part of this study. Specifically, we hypothesized that differences in the format of information (dog breed name or photographic image) would have an effect on the identification of a dog as supposedly dangerous. It was proposed that the name of the American Pit Bull Terrier has become so synonymous with DDA 1991 that it brings with it particularly negative connotations, and is therefore more likely to be correctly identified as a dangerous breed by name rather than by photographic image. In addition, it would be expected that images of a particular stocky morphological type such as the English Bull Terrier and Staffordshire Bull Terrier might be incorrectly identified by their appearance as dangerous dog types as listed in DDA 1991.

This would be an example of courtesy stigma, described by Goffman (1963) as a stigma acquired as a result of being identified as an individual who is related through social structure to a stigmatized individual—resulting in the treatment of both individuals in some respect as one (Goffman, 1963). In other words, it is expected that individual dogs of a stocky morphological type such as the Staffordshire Bull Terrier may be subject to courtesy stigma as a consequence of their physical resemblance to the highly stigmatized American Pit Bull Terrier.

The effects of these preconceptions are developed further in the second part of this study by looking at the effect of classification by dog group type (Terrier vs. Toy) on expectations of a range of behavioral characteristics, including aggressiveness, playfulness, fearlessness, and sociability. 
Which of these dog breeds do you believe are dangerous breeds as defined under the Dangerous Dog Act (1991)? Please tick one or more boxes.

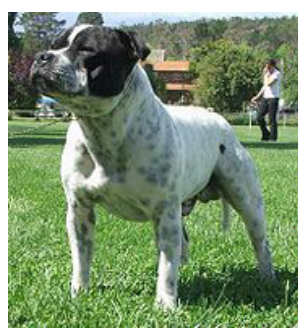

[1]

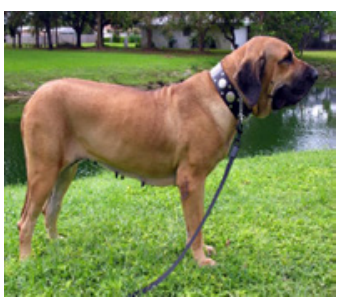

[4]

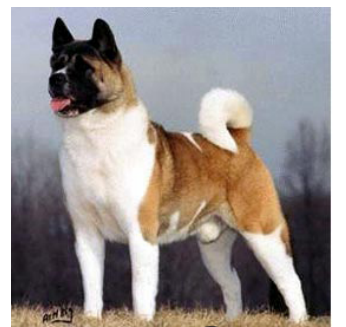

EPO

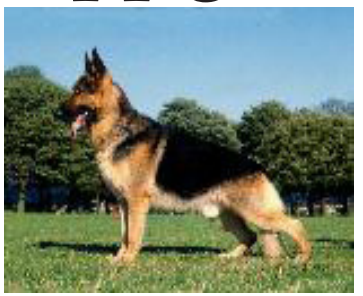

[5]

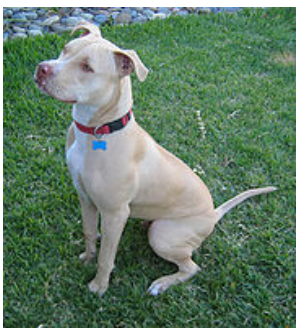

$[3]$

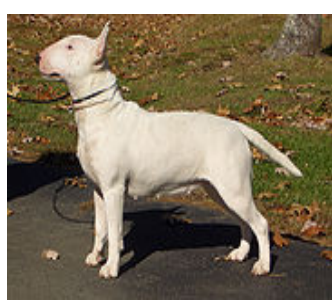

[6]

FIGURE 1 Photographic images courtesy of the UK Kennel Club (1, 2, 4, 5, and 6) and Wikipedia (3) included in the survey.

\section{Methods and Materials}

\section{Survey Design}

To address the first research question, a variation within a survey was used. Half of the distributed surveys included only images of six powerfully built breeds: Staffordshire Bull Terrier, Japanese Akita, American Pit Bull, Fila Brasiliero, German Shepherd, and English Bull Terrier (Figure 1). The remaining distributed surveys used only breed names. These six breeds were chosen because of their differing morphological appearances, but similar powerful build. The American Pit Bull Terrier and the Fila Brasiliero are both breeds named as dangerous dogs in DDA 1991. The images used in the study were provided by the UK Kennel Club, with the exception of the image of the Pit Bull Terrier, which is not recognized as a breed by the UK Kennel Club. For this breed type we conducted a Google search for American Pit Bull, and used the image used by Wikipedia, as it was the first image found by the search engine (Figure 1).

Respondents were invited to identify which dogs were dangerous as defined in the DDA 1991. Survey respondents were either offered images without names (Figure 1) or names without images. This allowed a comparison to be 
made relating to the differing modalities of the information provided, which helped determine the visual image or breed name's effects on the respondent's decision-making.

The second research question addressed the effect of dog breed group classification on assumptions of the behavioral traits they might exhibit. Respondents were offered a picture of a fictional breed-a Tskita. Half of the distributed surveys stated that the dog belonged to the Toy breed group and half identified this same dog as a Terrier. These breed groups are identified (Kennel Club (UK) 2003, 2011) as having distinct behavioral profiles. Respondents were invited to rate the dog's behavioral characteristics (on a scale from 1-10) using attributes derived from Svartberg and Forkman (2002): Playfulness, Curiosity/ Fearlessness, Very Chase-Prone, Sociability and Aggressiveness. This allowed for a comparison between respondents relating to the information they had regarding the dog's membership in these different breed groups (Figure 2).

\section{Subjects}

A pilot study indicated the value in targeting five relatively well-defined populations to obtain a good division between the features of gender, age, and cultural diversity over a more general survey approach of the UK population. Repetition of these findings in a revised survey would provide evidence of the reliability and robustness of these findings. Surveys were distributed by hand to respondents at their respective locations (i.e., at the veterinary surgery reception room, university, rescue center and local football team club house), with the exception of the surveys posted to the final group: homes in a residential area of North London. The 255 distributed surveys generated a response rate of $65 \%(166)$. Nearly half $(47 \%)$ of completed and returned survey responses came from Battersea Dogs and Cats Home (Table 1).

\section{Data Handling and Statistical Analyses}

Statistical analyses were conducted with spss 14. Chi-square tests and Odds ratios were used to identify differences in categorization. The Cochran Q test was applied to test whether the treatment (image or name) had a significant effect on responses that were used to test the hypothesis of interest to this study. Data generated from the scoring of behavioral characteristics of the Tskita according to whether the dog was attributed to being either a Terrier or Toy breed, were found to be non-normal (Kolmogorov-Smirnov test) and, therefore, the non-parametric Mann-Whitney test was used to assess the significance of any difference in the classification of the fictional breed on the ranking of each of the five behavioral characteristics. 
This is a breed of dog, known as the Tiskita. It is a small terrier breed type that originates from Vietnam.

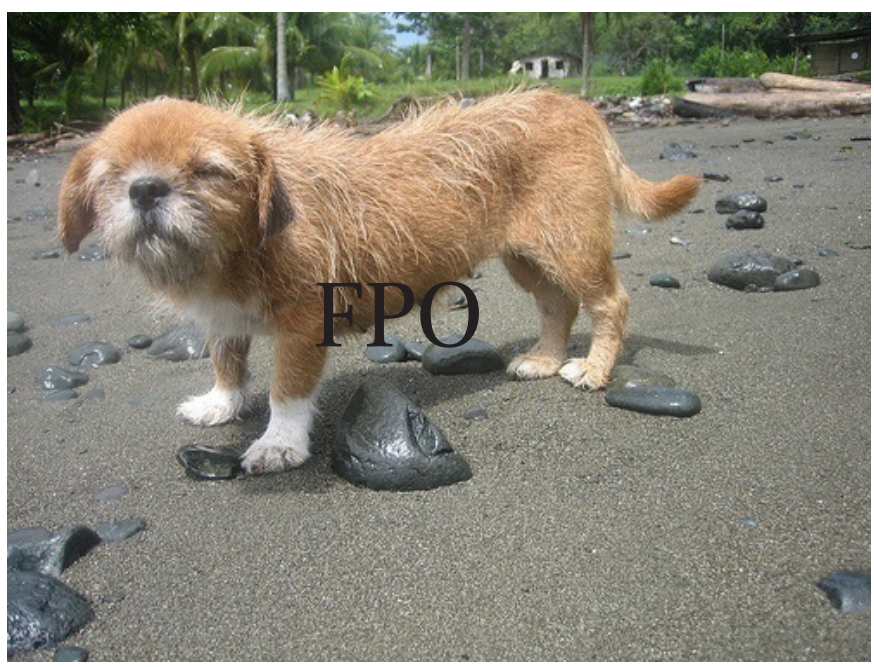

On a scale of 1 to 10 ( 1 being lowest and 10 being highest) from the above image please rank your perception of this terrier breed on the following behavioral characteristics?

\begin{tabular}{|c|c|}
\hline Playfulness & 12345678910 \\
\hline Curiosity/Fearlessness & 12345678910 \\
\hline Very Chase-proneness & $\begin{array}{lllllllll}12 & 3 & 4 & 5 & 6 & 7 & 8 & 10\end{array}$ \\
\hline Sociability & 1234 \\
\hline Aggressiveness & 123 \\
\hline
\end{tabular}

FIGURE 2 Survey question exploring public perception of behavioral characteristics dependent on breed group classification of a fictitious breed of dog (Tskita) as a member of the Terrier or Toy breed group. Photograph used in survey with permission from CMonster, Flikr.

Results

Effect of Image or Name on Ascribing Breeds to DDA 1991

Of the 166 surveys that could be used to assess the effect of image or name on ascribing breeds to DDA 1991, 81 (49\%) contained the images of the six breeds of interest and $85(51 \%)$ had the breed names. The proportion of respondents in each group correctly classifying breeds defined in the DDA 1991 (American Pit Bull Terrier and Fila Brasilerio) is illustrated in Table 2. 
TABLE 1 Five populations used in the main study.

\begin{tabular}{lcc}
\hline Populations & Count & Percentage \\
\hline Battersea Dogs \& Cats Home (Staff \& & 78 & 47.0 \\
Visitors) & 27 & 16.3 \\
N. London Football Club & 21 & 12.7 \\
Residential_-Road, N. London & 22 & 13.3 \\
Veterinary Surgery Reception Room, & & \\
N. London & 18 & 10.8 \\
Lincoln University Animal Science & & \\
students & 166 & 100.0 \\
Total & & \\
\hline
\end{tabular}

TABLE 2 Datafor 6 breed types included in the survey.

\begin{tabular}{llllllll}
\hline Breed & $\begin{array}{l}\text { Asymptotic } \\
p \text {-Value }\end{array}$ & $\begin{array}{l}\text { Correct \% } \\
\text { Image }\end{array}$ & $\begin{array}{l}\text { Correct } \\
\% \text { Name }\end{array}$ & $\begin{array}{l}\text { Odds } \\
\text { Ratio }\end{array}$ & $\begin{array}{l}\text { 95\% CI } \\
\text { Lower }\end{array}$ & $\begin{array}{l}95 \% \text { CI } \\
\text { Upper }\end{array}$ & $\begin{array}{l}\text { Chi- } \\
\text { Squared }\end{array}$ \\
\hline $\begin{array}{l}\text { Staffordshire } \\
\text { Bull Terrier }\end{array}$ & $<0.001$ & $46.3 \%$ & $81.3 \%$ & 5.04 & 2.47 & 10.27 & 21.2 \\
$\begin{array}{l}\text { Japanese Akita } \\
\text { American }\end{array}$ & 0.022 & $74.7 \%$ & $69.0 \%$ & 2.68 & 1.13 & 6.31 & 5.3 \\
$\begin{array}{l}\text { Pit Bull Terrier } \\
\text { (DD })\end{array}$ & & $70.0 \%$ & $98.8 \%$ & 0.03 & 0.00 & 0.23 & 25.1 \\
$\begin{array}{l}\text { Fila Brasiliero } \\
\text { (DD })\end{array}$ & 0.024 & $23.8 \%$ & $40.5 \%$ & 0.46 & 0.23 & 0.91 & 5.1 \\
$\begin{array}{l}\text { German } \\
\text { Shepherd Dog }\end{array}$ & 0.118 & $90.0 \%$ & $96.3 \%$ & 2.85 & 0.73 & 11.17 & 2.4 \\
$\begin{array}{l}\text { English } \\
\text { Bull Terrier }\end{array}$ & 0.002 & $65.0 \%$ & $86.3 \%$ & 3.38 & 1.54 & 7.40 & 9.8 \\
\hline
\end{tabular}

Note. DD = Breeds defined as “dangerous dogs" under the uk Dangerous Dogs Act, 1991. 
The results demonstrated significant differences between responses from surveys with breed images and surveys with breed names in their identification of dangerous dogs as named in the DDA 1991. The Cochran Q test indicated that the proportion of correct identifications varied between the 6 breeds $(p<0.001)$, and for many breeds accuracy differed between the name and image surveys. The breed that was most consistently correctly identified as not being covered by DDA 1991 was the German Shepherd Dog. This is the fourth most popular breed registered in the United Kingdom in 2010 (The Kennel Club, pers.com), so the dog is potentially more familiar to respondents.

In contrast the Fila Brasileiro, a breed that is not well known in the UK, but nevertheless named in DDA 1991, was least likely to be correctly identified. It is noteworthy that respondents were generally less accurate with images than names, with 4 out of 6 breeds more accurately ascribed by name alone than image alone, the exceptions being the German Shepherd Dog and Japanese Akita. While the majority of respondents correctly identified both dogs as not included in DDA 1991, 1 in 10 of respondents presented with the German Shepherd Dog image and a quarter of respondents presented with the Akita considered these to be dogs who would be proscribed by DDA 1991.

The bull terrier types also showed a greater chance of being mis-ascribed by image alone. Both the Staffordshire Bull Terrier and English Bull Terrier were correctly identified as not being "dangerous dogs" based on name alone by over $80 \%$ of respondents; however, this declined to $65 \%$ based on image alone for the English Bull Terrier and less than 50\% for the Staffordshire Bull Terrier. As a consequence, respondents were over 3 times more likely to mis-ascribe the English Bull Terrier by image alone, an Odds-Ratio that rose to over 5 times for the Staffordshire Bull Terrier. For the American Pit Bull Terrier, only 1 out of 85 surveys using names failed to identify the dog as being covered in DDA 1991, while $30 \%$ failed to correctly ascribe the dog when presented with the image alone, confirming the difficulties of identifying American Pit Bull terriers or pit bull types by appearance alone.

\section{Effect of Classification on Perception of Behavioral Characteristics}

Of the completed and returned surveys, 79 (48.8\%) included the descriptor of the Tskita as belonging to the Terrier breed group and $83(51.2 \%)$ attributed it to the Toy breed group. The difference in the classification of the fictional animal as either a Toy or Terrier had a significant effect on the ranking of each of the five behavioral characteristics (Table 3). The Terrier classification was significantly different from the Toy classification in playfulness (Mann-Whitney $U$-test; $\mathrm{U}=4.475, p<0.001)$, curiosity and fearlessness $(U=8.173, p<0.001)$, very 
chase prone $(U=9.083, p<0.001)$, sociability $(U=2.870, p=0.004)$ and aggressiveness $(U=6.657, p<0.001)$. Use of the classification Terrier attracted higher scores in relation to type-specific characteristics such as curiosity and fearlessness, chase proneness, and aggressiveness. In contrast usage of the classification Toy resulted in higher scores for type-specific characteristics such as ratings for sociability (Table 3 ).

TABLE $3 \quad$ Number of respondents and differences in median and mean in scoring 5 behavioral characteristics relating to the classification of the Tskita as Toy or Terrier.

\begin{tabular}{|c|c|c|c|c|c|c|}
\hline Behavioral & Number & Median & Mean & Standard & IQ & Standard \\
\hline Characteristics & & & & Deviation & & Error \\
\hline
\end{tabular}

Playfulness

Terrier

Toy

Total

$\begin{array}{rrrrrr}79 & 6.00 & 6.19 & 1.60 & 2.00 & 0.18 \\ 83 & 5.00 & 4.82 & 2.01 & 3.00 & 0.22 \\ 162 & 5.00 & 5.49 & 1.94 & 1.00 & 0.15\end{array}$

Curiosity \& Fearless

$\begin{array}{lrrrrrr}\text { Terrier } & 79 & 8.00 & 7.53 & 1.58 & 2.00 & 0.18 \\ \text { Toy } & 83 & 4.00 & 4.47 & 2.02 & 3.00 & 0.22 \\ \text { Total } & 162 & 6.00 & 5.97 & 2.38 & 1.00 & 0.19\end{array}$

Very Chase-Prone

$\begin{array}{lrrrrrr}\text { Terrier } & 79 & 9.00 & 7.88 & 2.04 & 2.00 & 0.23 \\ \text { Toy } & 83 & 3.00 & 3.69 & 1.99 & 3.00 & 0.22 \\ \text { Total } & 162 & 6.00 & 5.73 & 2.90 & 1.00 & 0.23\end{array}$

Sociability

$\begin{array}{lrrrrrr}\text { Terrier } & 79 & 5.00 & 5.47 & 1.57 & 2.00 & 0.17 \\ \text { Toy } & 83 & 7.00 & 6.31 & 2.07 & 3.00 & 0.23 \\ \text { Total } & 162 & 6.00 & 5.90 & 1.89 & 1.00 & 0.14\end{array}$

Aggressiveness

\begin{tabular}{lrrrrrr} 
Terrier & 79 & 5.00 & $5 \cdot 47$ & 2.09 & 3.00 & 0.24 \\
Toy & 83 & 3.00 & 3.17 & 1.72 & 3.00 & 0.19 \\
Total & 162 & 4.00 & 4.29 & 2.23 & 0.00 & 0.19 \\
\hline
\end{tabular}




\section{Discussion}

In this study the use of the type classification for informing public perceptions of dog behavior was explored. The two research topics of interest were the identification of "dangerous" dog types as defined in the DDA 1991 by survey respondents, and the effect on identification relating to the material offered (i.e., only the name of the breed or only a photographic image; and the effect dog breed group classification may have on the survey respondents' ratings of particular behavioral traits).

The results revealed that the Staffordshire Bull Terrier was five times more likely to be incorrectly identified as a dangerous breed by photographic image than name. This may be explained by the dog's resemblance to the image of the squat, powerfully built bull terrier type commonly reported in the media as posing a threat to public safety. This Courtesy Stigma (Goffman, 1963) and misidentification may be explained by humans' sensitivity to visual information facilitating necessary biological adaptive actions, such as fleeing from threats of danger. In the example of the DDA 1991, type is the discriminating category used to distinguish dangerous dogs from others. It is therefore unsurprising that dogs resembling the broad morphological type of the American Pit Bull Terrier, such as the Staffordshire Bull Terrier were incorrectly identified as one of the "dangerous" breeds listed in the Act.

As expected fewer respondents correctly identified the American Pit Bull Terrier as a dangerous dog by image only than by name alone. This is unsurprising, as it has been argued that the term pit bull has been demonized in public understanding, and maintains a high media profile in dog attack reports. In contrast, even experienced dog observers find it difficult to differentiate between similar breeds based on morphology alone (Voith, Ingram, Mitsouras, \& Irizarry, 2009; 2013; Hoffman et al., 2014), and reports of pit bull attacks have been inflated due to reporters being unable to tell pit bulls apart from other bull breeds (see Delise, 2007; Patronek et al., 2013).

This profiling by image alone would merit further investigation; we had used a common publically available image of American Pit Bull, as no UK Kennel Club stock image was available. This image of a dog in a sitting posture, contrasted with the standing or "show" postures of the 5 other breeds (in particular the Staffordshire Bull Terrier) may have influenced respondents' tendency to consider the dog as potentially dangerous. A dog's posture significantly affects our reading of temperament (correctly or otherwise) (Taylor \& Mills, 2006; Meints \& de Keuster, 2009), so we cannot rule out the posture in the image having some influence on responses. 
Our expectation would be that while a more formal "show" pose may make American Pit Bull Terriers look more intimidating and potentially more dangerous, there would still be a lower proportion of respondents accurately assigning dogs as a dangerous breed as defined by DDA 1991, based on image alone, due to the uncertainty of determining breed type by morphology. Nevertheless, an investigation of the effect of posture on recognition or attribution of personality traits would make a useful additional study to further understand how media images influence impressions of breed types.

The findings of this study demonstrate that the classification and categorization of breeds has a powerful effect on personal perception and expectations regarding behavioral traits. The classification Terrier attracted higher scores in relation to type-specific characteristics such as aggressiveness, as well as playfulness and fearlessness, in contrast to when the fictional breed was classified as a Toy. Despite research suggesting that breed type alone is a poor indicator of aggression towards humans (Sacks et al., 2000; Seksel, 2002; Delise, 2007; Braem et al., 2008), our results indicate that as a member of the Terrier breed group, there may be a bias towards perceiving breeds such as the Staffordshire Bull Terrier as manifesting higher levels of "aggressiveness."

These findings of personal perception of breeds also have serious implications for dog welfare. Like human racism, type classifications seemingly satisfy a human need to reduce a complex multi-dimensional issue to a simplistic and populist one-dimensional factor (Clarke, Cooper \& Mills, 2013). Instead the nature of the dog and the animal's behavior needs to be recognized as a biological and cultural product-behavior cannot be understood divorced from humans and cultural context.

The creation of the Pit Bull Terrier as a folk devil by the UK tabloid media contributes to the demonization of dogs in general, and Staffordshire Bull Terriers in particular, serving to undermine public appreciation of dogs. Staffordshire Bull Terriers and their caretakers face additional challenges in relation to breed-specific legislation as a result of the courtesy stigma applied to them. Members of this breed type are commonly misclassified as dangerous dogs, resulting in their inappropriate seizure, kenneling, and destruction, alongside feelings of grief and loss experienced by families involved. Of the dogs escaping destruction and placed in kennels for re-homing, many remain there for lengthy periods, as dog breed stereotypes are ingrained and significantly affect dog adoptability (Wright et al., 2007).

It is suggested that the Staffordshire Bull Terrier is an example of a particular type commonly perceived as dangerous' under the DDA 1991, even though the 
dog is not named in the Act. The current Kennel Club breed standard describes this dog as "bold, fearless, and possessing indomitable courage and tenacity" (Kennel Club, 2011). For some individuals there may be some social cachet in having such a dog type. Therefore, rather than focusing on the somatotyping inherent in breed-specific legislation, it is suggested that a more relevant line of enquiry would be to address caregiver social psychology and the nature of dog-human interaction.

A geographically focused nationwide database of dog bite information may assist in this endeavor to target areas where supposedly dangerous dogs are identified. This would perhaps allow a fuller and more comprehensive cultural perspective on this issue to develop that would include an exploration of the effects of extrinsic environmental factors on behavioral outcomes. In addition, it is likely to yield a more constructive way forward to address the issue of "dangerous dogs" and the purported aim of the DDA 1991: to safeguard the public.

\section{Conclusion}

A culture of fear and increasing risk aversion by western societies (Furedi, 2006) has perhaps led to the development of an over-reliance on perceiving particular dog types as dangerous and minimizing/ignoring other cultural variables at play in the manifestation of dog aggression. Clearly, caution should be applied in making generalizations about breed-specific behaviors based on type, which is divorced from any social, political, and cultural context. These findings suggest that there is a need to challenge notions that behavior is the simple product of a biologically determinist process within the individual and to address the social construction of images and perceptions of breeds and the functions these serve. Such action is necessary if we wish to maintain a positive relationship with dogs, effectively control the risks associated with dog guardianship, and capitalize on the benefits they bring to society.

\section{Acknowledgments}

We would like to thank the UK Kennel Club for access to photographic images, Battersea Dogs \& Cats Home for help in distributing surveys, and Lynda Birke and Nelly Lakestani for feedback on Tracey Clarke's PhD thesis. 


\section{References}

Askew, H. R. (1996). Treatment of behavior problems in dogs and cats: A guide for the small animal veterinarian (2nd ed.). Oxford: Blackwell Publishing.

Becker, H. (1963). Outsiders: Studies in the sociology of deviance. New York: Free Press.

Bellwood, P. (2004). First farmers: The origins of agricultural societies. Oxford: Blackwell Publishing.

Bennett, P. C., \& Rohlf, V. I. (2007). Owner-companion dog interactions: Relationships between demographic variables, potentially problematic behaviours, training engagement and shared activities. Applied Animal Behaviour Science, 102(1), 65-84.

Bradshaw, J. W. S., \& Goodwin, D. (1998). Determination of behavioral traits of purebred dogs using factor analysis and cluster analysis; a comparison of studies in the USA and U K. Research in Veterinary Science, 66(1), 73-76.

Braem, M., Doherr, M. G., Lehmann, D. \& Mills, D. (2008). Evaluating aggressive behavior in dogs: a comparison of 3 tests. Journal of Veterinary Behavior: Clinical Applications and Research, 3(4), 152-160.

Byrne, E. (2009). My weapon is a dog. Documentary Aired 08.31.09, ввС Three, UK.

Clarke, T., Cooper, J. \& Mills, D. (2013). Acculturation-perceptions of breed differences in behavior of the dog (Canis familiaris). Human-Animal Interaction Bulletin, $1(2), 16-33$.

Clutton-Brock, J. (1984). Dog. In I. L. Mason (Ed.), Evolution of domesticated animals (pp. 198-210). London: Longman.

Cohen S. (2002). Folk devils and moral panics (3rd ed.). Oxford: Routledge.

Coltrane, S., \& Messineo, M. (2000). The perpetuation of subtle prejudice: Race and gender imagery in 199os television advertising. Sex Roles, 42(5-6), 363-389.

Cowell, A. (2014). Pistorius versus the pit bull: fierce prosecuter shares stage. Retrieved from www.nytimes.com/2014/04/14/world/africa/pistorius-murder-trial.html.

Crist, E. (1999). Images of animals: Anthropomorphism and animal mind. Philadelphia: Temple University Press.

Dangerous Dogs Act. (1991). Dangerous Dogs Act 1991 \& 1997 Amendment. Retrieved October 10, 2014, from www.legislation.gov.uk/ukpga/1991/65.

Delise, K. (2007). The pit bull placebo: the media, myths and politics of canine aggression. Sofia: Anubis Publishing.

Dennis-Bryan, K., \& Clutton-Brock, J. (1988). Dogs of the last hundred years at the British Museum. London: Natural History Museum Publications.

Furedi, F. (2006). Culture of fear revisited. London and New York: Continuum.

Gladwell, M. (2006). Troublemakers: What pit bulls can teach us about profiling? The New Yorker, 81, 38-43.

Goffman, E. (1963). Stigma: Notes on the management of spoiled identity. New York: Prentice-Hall. 
Hall, S., Critcher, C., Jefferson, T., Clarke, J., \& Roberts, B. (1978). Policing the crisis: Mugging, the state, and law and order. Basingstoke and London: The Macmillan Press Limited.

Hansard. (1992). Retrieved October 10, 2014, from www.publications.parliament.uk/pa/ $\mathrm{cm} / \mathrm{cmhansrd}$.hwww.publications.parliament.uk/pa/cm/cmhansrd.

Harcourt, R. A. (1974). The dog in Prehistoric and early historic Britain. Journal of Archaeological Science, 1(2), 151-175.

Hiby, E. F, Rooney, N. J. \& Bradshaw, J. W. S. (2004). Dog training methods: Their use, effectiveness and interaction with behaviour and welfare. Animal Welfare, 13, 63-69.

Hoffman, C. L, Harrison, N., Wolff, L., \& Westgarth, C. (2014). Is that dog a pit bull? A cross-country comparison of perception of shelter workers regarding breed identification. Journal of Applied Animal Welfare Science, 17 (4), 322-339.

Jagoe, A. \& Serpell, J. (1996). Owner characteristics and interactions and the prevalence of canine behavior problems. Applied Animal Behavior Science, 47(1), 31-42.

Jones, O. (2012). Chavs: The demonization of the working class. London: Verso.

Kalof, L. (2007). Looking at animals in human history. London: Reaktion Books Limited.

The Kennel Club. (2003). The Kennel Club's illustrated breed standards (New ed.). London: Ebury Press.

The Kennel Club. (2011). The Kennel Club's illustrated breed standards: The official guide to registered breeds breed information (4th ed.). London: Edbury Press.

Levene, S. (1991). Dog bites to children. BMJ: British Medical Journal, 303(680o), 466.

Lodge, M., \& Hood, C. (2002) Pavlovian policy responses to media feeding frenzies? dangerous dogs regulation in comparative perspective. Journal of Contingencies and Crisis Management, 10(1), 1-13.

Mayr, E. (1999). Systematics and the origin of species, from the viewpoint of a zoologist. Cambridge: Harvard University Press.

Mehrkam, L. R., \& Wynne, C. D. L. (2014). Behavioral differences among breeds of domestic Dogs (Canis lupus familiaris): Current status of the science. Applied Animal Behavior Science, 155, 12-27.

Meints, K., \& de Keuster, T. (2009). Don't kiss a sleeping dog: the first assessment of "The Blue Dog" bite prevention program. Journal of Pediatric Psychology, 34(10), 1084-1090.

Oakes, P. J., Haslam, S. A., \& Turner, J. C. (1994). Stereotyping and social reality. Oxford: Blackwell Publishing.

Orritt, R., \& Harper, C. (2013). Similarities between the representation of "aggressive dogs" and "sex offenders" in the British news media. Accessed October 10, 2014, at https://www.inter-disciplinary.net/probing-the-boundaries/wp-content/ uploads/2014/05/orrittahpaper.pdf.

Oxford Dictionaries. Retrieved September 18, 2014, from http:www.oxforddictionaries .com. 
Patronek, G.J., Sacks, J.J., Delise, K. M., Cleary, D. V., \& Marder, A. R. (2013).Co-occurrence of potentially preventable factors in 256 dog bite-related fatalities in the United States (2000-2009). Journal of the American Veterinary Medical Association, 243(12), 1726-1736.

Podberscek, A. L. (1994). Dog on a tightrope: the position of the dog in British society as influenced by press reports on dog attacks (1988 to 1992). Anthrozoos, 7(4), 232-241.

Podbersceck, A. L., \& Serpell, J. A. (1997). Environmental influences on the expression of aggressive behavior in English cocker spaniels. Applied Animal Behavior Science, $5^{2}(3-4), 215^{-227}$.

Radford, M. (2001). Animal welfare law in Britain: Regulation and responsibility. Oxford: Oxford University Press.

Sacks, J., Sinclair, L., Gilchrist, J., Golab, G. C., \& Lockwood, R. (2000). Breeds of dogs involved in fatal human attacks in the United States between 1979 and 1998.Journal of the American Veterinary Medical Association, 217 (6), 836-840.

Seksel, K. (2002). Report to the NSw Department of Local Government on breed specific legislation issues relating to control of dangerous dogs. Seaforth: Animal Behavior Consultants.

Serpell, J. A. (1996). Evidence for an association between pet behavior and owner attachment levels. Applied Animal Behavior Science, 47(1), 49-6o.

Svartberg, K. (2006). Breed typical behavior in dogs-historical remnants or recent constructs? Applied Animal Behavior Science, 96(3-4), 293-313.

Svartberg, K., Forkman, (2002). Personality traits in the domestic dog (Canis familiaris). Applied Animal Behavior Science, 79(2), 133-156.

Takeuchi, Y., \& Mori, Y. (2006). A comparison of the behavioral profiles of purebred dogs in Japan to profiles of those in the United States and the United Kingdom. Journal of Veterinary Medical Science, 68(8), 789-796.

Taylor, K. D., \& Mills, D. S. (2006). The development and assessment of temperament tests for adult companion dogs. Journal of Veterinary Behavior: Clinical Applications and Research 1(3), 94-108.

Thurston, M. E. (1996). The lost history of the canine race-Our 15,0oo year love affair with dogs. Kansas: Universal Press Syndicate Company.

Tversky, A., \& Kahneman, D. (1973). Availability: A heuristic for judging frequency and probability. Cognitive Psychology, 5(2), 207-232.

Voith, V. L., Ingram, E., Mitsouras, K., \& Irizarry, K. (2009) Comparison of adoption agency breed identification and DNA breed identification of dogs. Journal of Applied Animal Welfare Science, 12(3), 253-262.

Voith, V. L., Trevejo, R., Dowling-Guyer, S., Chadik, C., Marder, A., Johnson, V., \& Irizarry, K. (2013). Comparison of visual and DNA-based breeds identification of dog and inter-observer reliability. American Journal of Sociological Research, 3(2), 17-29. 
Wan, M., Kubiniyi, E., Miklosi, A., \& Champagne, F. (2009). A cross-cultural comparison of reports by German shepherd owners in Hungary and the United States of America. Applied Animal Behavior Science, 121(3-4), 206-213.

Wright, J. C., Smith, A., Daniel, K., \& Adkins, K. (2007). Dog breed stereotype and exposure to negative behaviour: Effects on perceptions of adoptability. Journal of Applied Animal Welfare Science, 10(3), 255-265.

AQ: Please provide individual jpegs. 